\title{
Endosteal sclerosis-cerebellar hypoplasia syndrome
}

INSERM

\section{Source}

INSERM. (1999). Orphanet: an online rare disease and orphan drug data base. Endosteal sclerosis-cerebellar hypoplasia syndrome. ORPHA:85186

Endosteal sclerosis-cerebellar hypoplasia syndrome is characterized by congenital cerebellar hypoplasia, endosteal sclerosis, hypotonia, ataxia, mild to moderate developmental delay, short stature, hip dislocation, and tooth eruption disturbances. It has been described in four patients. Less common manifestations are microcephaly, strabismus, nystagmus, optic atrophy, and dysarthria. It is appears to be transmitted as an autosomal recessive trait. 